This item was submitted to Loughborough's Research Repository by the author.

Items in Figshare are protected by copyright, with all rights reserved, unless otherwise indicated.

\title{
Social intelligence for developing countries: the role of grey literature
}

PLEASE CITE THE PUBLISHED VERSION

PUBLISHER

(C) Emerald

LICENCE

CC BY-NC-ND 4.0

\section{REPOSITORY RECORD}

Sturges, R. Paul. 2019. "Social Intelligence for Developing Countries: The Role of Grey Literature”. figshare. https://hdl.handle.net/2134/556. 


\title{
Social intelligence for developing countries: the role of grey literature
}

\author{
P. Sturges \\ Department of Information Science, Loughborough University, Leicestershire, LE11 3TU, \\ United Kingdom \\ Published in Collection Building (1999) 18 114-125.
}

\begin{abstract}
The necessity for social intelligence, broadly defined, to inform decision-making in developing countries is apparent as globalization places increasing demands on governments, nongovernmental organizations (NGOs), parastatals, and business corporations. Yet the existing information systems of developing countries suffer from a range of problems which afflict all three main elements: documentary services (libraries and information centres), statistical services, and management information systems (including records management and computerized systems). Grey literature is vital to each of these three systems, either as the partially-processed product of the internal information generating capacity of the country itself, or in the external scanning process. Information professionals have tended to concentrate on the technical problems of acquiring, listing, indexing, retrieving and alerting potential users to documents. this largely ignores questions about the capacity and propensity of the targeted users to absorb information, however well it might be organized by information systems. An examination of the decision making process in a selected country (Malawi) and a case study of planning for technology transfer (from Kenya) are used to illustrate these problems and the role of intelligence. A range of structural and nonstructural constraints on the absorption of information is identified. The conclusion is that the problems of existing information systems can only be relieved by information professionals further processing and refining the information content of grey literature so as to present it to the decision-makers in the form of intelligence reports.
\end{abstract}

\section{INTRODUCTION}

Social intelligence is a term which has been defined in so many different ways that it may sometimes seem too vague to be useful. However, it does sum up a particular approach to knowledge so well that it is valuable despite such doubts. It is defined by Cronin and Davenport as a 'process whereby a society, organization or individual acquires information in the widest sense, processes and evaluates it, stores and uses it for action'.[1] Perhaps the most important part of this definition is the emphasis on using information for action, and this has been the emphasis used by Stevan Dedijer, whose influential teaching and writing first focused around the term in the mid 1970s. It is apparent from studies assembled by Dedijer and Jequier[2] that there is a considerable necessity in developing countries for an enhanced capacity to use social intelligence to inform decision-making. In this paper the information systems available in developing countries and the context in which they operate, will be examined to show their capacity to provide intelligence for decision-makers. The way in which the content of grey literature needs to be fed into the social intelligence process will be illustrated with case studies.

Specific needs for intelligence have previously been identified by commentators such as 
Wolfgang Stolper, who in 1966 drew attention to the paucity of information for use in the planning process in newly-independent Nigeria.[3] Stolper pointed out that there was insufficient information available to the planner on such utterly basic aspects of the country's physical environment as its soils and rainfall. He also drew attention to the lack of knowledge of social structures, traditional culture and beliefs, patterns of land tenure, and many other aspects of people's everyday lives which influenced their development needs, and the acceptability of one programme or project, as opposed to another. Some of these areas of ignorance concerned conditions which might seem to have been permanent or unchanging, and where the need for information could be satisfied by a single research exercise. Most, however, concerned aspects of life which are dynamic and which call for constant observation and monitoring. This points to the need for data-gathering capacity established on a permanent basis. Even though this is difficult to install and potentially expensive, the satisfaction of such information needs can at least be seen as well within the scope of governments and other organizations, since the basic data is available from inside the national boundaries. This is only part of the picture, however, and probably always was only part. Certainly today the whole range of information needed for decision making is much more extensive and can definitely not be satisfied from local sources alone.

\section{GLOBAL INFLUENCES}

In the 1990s a process of globalization began to sweep the developing world up into the trends affecting the industrialized countries in a way which has made the need for information more acute than ever. Globalization has many facets, most of which are relevant to the subject of this paper in some way or other. Like all large, unifying concepts, globalization attracts cliche, and sometimes seems inexpressible without overused and shallow generalizations. Nevertheless, there are clearly a number of processes which are tending to draw people from all parts of the world together in one global, shared community. Some of these are: communications technology (ISDN, Internet, etc.); financial interdependency (as expressed by the indebtedness of large parts of the world to the financial institutions of the industrialized North); removal of trade restrictions (particularly through GATT, the General Agreements on Trade and Tariffs); international media and the associated cultural homogenization (through TV, films, books, recorded music, etc.); the trade in intellectual property (as mediated by GATT's TRIPS, the international agreement on Trade-Related Aspects of Intellectual Property); multinational business generally (marketing the same products worldwide and manufacturing wherever the financial advantage lies); the activities of the USA, United Nations, European Community and others, as global policemen, intervening in disputes to keep the peace or preserve aspects of the status quo; the ubiquity of certain languages particularly, but not exclusively, English. It is easy to look at the various elements of this brief glance at globalization and recognise the information content or implications of virtually all. The first of these (communications technology) deserves an extra word at this point because of its over-riding significance.

It is worth re-asserting that the power of computing, linked to the capacity of modern telecommunications systems to carry great volumes of data at speeds that are in human terms more or less instantaneous, now effectively destroys the isolation of any part of the world. A developing global information infrastructure promises interconnection without difficulty anywhere on the planet. Local networks are linked to national networks, which in turn communicate with each other via satellites and cabling. Open computer systems offer data and information of a myriad kinds to those who have the (increasingly affordable) equipment. The assistance of the World Wide Web (WWW) enables comparatively well-focused searching 
through world information resources. Facilities such as computer shopping, delivery of video and other entertainment media by the same means are beginning to be very widely available, and the potential for a bewildering mix of personal and public communication has become one of the cliches of the information age.

Discussing this in relation to less developed countries sometimes seems a compound of pious hopes rather than reality, but very many aspects of information globalization are becoming real even, for instance, in comparatively poor African countries. To governments barely able to manage the conventional forms of information transfer, this must have nightmare qualities. Flows of data across national boundaries (transborder data flow) relating to the work of banks, airlines and business corporations have been commonplace for years. Once governments have allowed organisations to possess computers and to connect them to telecommunications systems, the ability to monitor and control transactions in currencies, the travel arrangements of individuals, or the dealings of companies in the nation's products, is effectively lost. What is more, the individual citizen can quite easily share this lack of restraint on communication and obtain facts, figures and ideas previously restricted both by access problems and official disapproval. The other side of this, from the government point-of-view, is that access to enormous volumes of information, previously inaccessible because of the clumsiness of recording and transmitting information on paper, can now potentially be employed to their advantage. The Internet is not just a medium for the enthusiastic individual. To cite only one example of the abundant documentation from governments and NGOs, the availability of thousands of US government documents on the WWW allows access not merely to great volumes of data, but vital insights into American official thinking and ways of working. The volume of this can scarcely be exaggerated and, if it can be exploited properly, it goes a long way towards enabling an organization in a developing country to operate at a strategic level. Yet, so far the governments of most developing countries have not made effective use of the global information wealth that is waiting for them, and globalization has often been seen as more of a threat than a series of opportunities.[4]

\section{GLOBALIZATION AND THE POLITICS OF INFORMATION}

In the 1980s Rita Cruise O'Brien drew attention to significant aspects of the issue of globalization for less developed countries, largely drawing in evidence from Latin America.[5] In effect, she took Stolper's arguments, which mainly applied to internally generated information, and applied them to the external information environment of the developing country. In particular, she showed how the negotiating power of the less developed countries in relation to the industrialized world was profoundly impaired at that time by the former's inability to access the global information networks. The developments covered by O'Brien's book took place in the context of a crucial aspect of globalization for less developed countries, the manipulation of their economies, as an indebted and dependent periphery of the global financial market. The growing indebtedness of developing economies since the nineteen sixties was such that by the world recession of 1979-81 many could not service their existing debts. In Africa, for instance, these amounted to an average of 75 per cent of Gross Domestic Product (GDP) across the continent. At the same time, declining economic circumstances called for further external support. It was at this time that the World Bank and the International Monetary Fund (IMF) began to apply Structural Adjustment Programmes (SAPs) with rigour. The IMF, from 1979, and the World Bank, from 1980, offered loans to governments, conditional upon meeting sets of policy requirements for the adjustment of their economies. These SAPs were designed to shift economies away from state intervention towards market-led policies. This had the particular 
intention of reviving agricultural production as a necessary basis for a sound economy. The change was to be achieved by devaluation of currencies, reduction of state expenditure and of subsidies favouring the urban/industrial population. This has been a painful process and SAPs have been identified as the direct cause of considerable suffering amongst the population at large through sharp rises in unemployment, falls in the real value of earnings, and the deterioration of social welfare, health, education and other essential services. This has seemed to very many of those who have commented on SAPs as an impossibly high price to pay for a switch from unsuccessful state intervention to reliance on a form of market mechanism more or less untested in the circumstances of many developing countries.[6]

SAPs can be seen not only as based on a critique of the quality of state intervention in the economy, but, by extension, also as a commentary on the quality of the intelligence used in planning such interventions. The ministries of planning that had been dominant in many developing countries were effectively damned by this approach. They were seen as inflexible monoliths, incapable of reacting to information about circumstances, even if they had the will to do so. By and large, the SAPs favoured subject ministries, whose supposed greater knowledge and expertise in fields such as transport, agriculture, education and health was seen as more likely to result in realistic plans. In fact, such ministries may have been little better, vulnerable at precisely those points in their structure where information is crucial. Indeed, one writer specifically suggests that,

It has to be recognised that these ministries have been, and are likely to remain, very weak at the policy-analytical level.[7]

In Africa it has, nevertheless, been possible to identify an ongoing debate on the role of information in the continent's future, between the proponents and opponent of SAPs from the early 1980s onwards. This dialogue was basically between, on the one hand, the World Bank and the IMF, and, on the other, the Organisation for African Unity (OAU) and the UN's Economic Commission for Africa (ECA). The first important contribution to the debate was the OAU's Lagos Plan of Action, which was agreed in 1980. This had a number of significant things to say about the role of information in development. For instance, on agriculture, the Plan concluded that research findings needed to be made available to the farming community without delay. It accordingly recommended a closer link between research and extension services, and greater emphasis on the spread of proven technologies. The section dealing with industry similarly contained two elements with a strong information significance. It called for the exchange of information among African states on the technical and financial specification of development projects, as a contribution to economic cooperation, and also the creation of institutions to make inventories of shared national resources.

Information on natural resources was identified very strongly as a basic need. The Plan acknowledged that most African countries did not have a full knowledge of their own natural resources, whilst transnational corporations, in contrast, held a great deal of such knowledge. A series of specific proposals were made in response to this, including government assertion of control over the results and basic data (maps, plans, films, logs, etc.) of commercial prospecting. It was recommended that national surveying and mapping institutions should be strengthened, and that national documentation centres be set up to ensure the best possible storage and use of data, including geological documentation, reports, and surveys. The section dealing with science and technology was quite explicit on the potential contribution of information, pointing out that,

Lack of information is one of the most serious obstacles to selection, acquisition, and use of appropriate technology options. An understanding of the local environment, character 
and orientation of the transferees is as important as information on the technology to be supplied.[8]

The Plan went on to recommend the establishment or strengthening of national technology information centres, liaison between such centres on a regional level, and the undertaking of studies on agricultural and industrial extension services, so as to obtain improved feedback on their effectiveness.

Almost contemporaneously, in 1981, the Bank published a major policy document in the form of its report Accelerated development in sub-Saharan Africa.[9] Whilst its central concern was also economic, it too contained significant statements about information. It identified significant weaknesses in the use of information in public sector decision-making of the type already discussed here. As part of its prescription for the future the Bank suggested intensifying efforts in the areas of knowledge creation and data analysis and a significant strengthening of Africa's statistical services. Specific mention was made of the need for more information on topics such as rainfall, river flows, soil quality, farming systems, and patterns of land use, precisely as Stolper had argued many years before.

The two sharply opposed viewpoints of those who advocated SAPs, and those who proposed a revisionist African development programme, continued to be debated and refined during the 1980s. However, the sense that the quality of information was both a key to the effectiveness of the arguments of the opposing parties, and an important part of any formula for African economic recovery stayed constant. The World Bank continued to have important things to say about information. In Sub-Saharan Africa: from crisis to sustainable development[10], possibly its most significant report of the 1980s, it again drew specific attention to the poverty of Africa's knowledge base. It criticised the inappropriateness of most of Africa's data as well as the techniques employed to collect it, citing: under-funded statistical services, the low priority given to data collection by governments, gaps in the data relating to every sector, inappropriate use of information technology, and an inability to get information to the decision makers. Its recommendations prioritized four main areas: social and demographic data, natural resources and the environment, price and production statistics, and national accounts. It strongly recommended the rehabilitation and strengthening of national statistical and information systems. This was seen as permitting a fundamental shift from decision-making based on speculation and conjecture to an approach based on reliable quantitative information.

In the 1990s the World Bank further confirmed its commitment to the importance of information with a program initiative called InfoDev,

To harness the technology to link people together and to leverage its impact for development, both accumulating the right kind of knowledge and helping our clients to build the capacity to use it.[11]

The Bank now sees itself as having a major role in information sharing, and has begun to fund projects with a view towards both their information role, and the information support available to assist their progress. In particular the Bank has sought an alliance with the ECA whose own African Information Society Initiative( AISI) addresses the same themes.[12] InfoDev and AISI represent a sign that after many years of debate a consensus is emerging between these major players as to what is needed to give information a genuine role in African planning and decision making. Encouraging though this is, it is still only something which might be formally acknowledged at the rarefied levels inhabited by Government Ministers, senior civil servants and the upper hierarchy of international organisations. Lower down the information chain where the activity that matters must take place things still have changed little. 


\section{THE INFORMATION INFRASTRUCTURE}

Indeed, in 1992, in an article introducing the topic of Information Management in Africa, Kingo Mchombu still felt it necessary to point out that:

One of the hallmarks of a good African civil servant or manager is the ability to take decisions without having all the relevant information.[13]

Today this is not usually because of the absence of an information infrastructure intended to ensure a flow of information to those who need it. In most cases there are elements of such an infrastructure in place. The nature of that infrastructure is worth noting at this point. What one might expect to find in an African organisation are several different types of service. These can be categorized in various ways, and the extent to which any particular category is present in a given organisation varies. Cook, for instance, suggests a fourfold division of information infrastructural services.[14]

He suggests that, first of all, one is likely to find a library and documentation service, essentially handling printed materials arriving from outside the organisation itself. These would range from books and journals to a great range of grey literature. Such a service would also be increasingly likely today to use computers for some purposes. Second, there could be a records management system which would organize current filing systems for mail, memoranda and other internally-generated documents, some of which might be described as grey literature. It would also provide care for non-current documents so that they could be retrieved when needed, and eventually it would appraise the content of the files for retention as archive or, alternatively, disposal. Third, there might be data systems provide by a computer services section. This would look after all aspects of computing, from word-processing and other software used in administration, through to data-processing services which could handle statistical data on behalf of the organisation. Finally, there might a communication service handling postal arrangements, telephones, fax, electronic mail, video conferencing and other such services.

Another way of looking at fundamentally the same group of services, would treat them under four different headings - administrative, documentary, statistical and information technology. The first, administrative, category conforms fairly closely to that described above as a records management system. There is also an implication that the emphasis is more on the current exploitation of the internal documentation of the organisation than on its longterm fate. The second, documentary, category corresponds almost exactly with the library and documentation services described above. The third, statistical, service rather reflects practice in official bodies than in business corporations. Statistical services have long been provided in government ministries and parastatal organisations to collect, process and present data to the decision makers. The collecting and processing aspect of their work would tend to fall within the data-processing part of what was described above as a data systems service. It should be noted, however, that many organisations are moving from data-processing services, as such, towards providing a fully-fledged statistical unit, which is required to present data at least partially interpreted for management use. Finally, an IT section combines all, or most, aspects of a data systems service and a communications service, so as to provide integrated technology platforms for the work of the organisation.

It is not so much how the various services are categorized, or how they are separated or combined within any given organisation that matters. The point is that an infrastructure with elements that would be easily identifiable in terms of either of the above typologies is present in 
most large organisations in developing countries, whether in the public or the private sector. It may be somewhat embryonic, or ill-balanced, but it will be there. Yet the existence of an infrastructure consisting of all or some of these types of service does not ensure that information actually plays the part in the decision making process that ideally it should. The status of grey literature is naturally significant across these services, and it is patently obvious that such resources are not exploited to anything like their basic capacity, let alone their full potential. A detailed analysis of just one aspect of the exploitation of the information content of grey literature supports this contention. By looking at the role of grey literature in information service to the rural population by Agricultural Extension Services it can be seen that not merely is the capacity for acquiring and organizing grey literature inadequate, but that there is insufficient ability to repackage the information content for re-use.[15] A more detailed examination of how information services in Malawi compile information packages for dissemination in the rural areas, confirms this generalization.[16] Arguably, this relates directly to disfunctions in the national capacity to handle and exploit information and intelligence at all levels, which can be directly traced to key aspects of the political economy of the states concerned.[17] Certainly the use or non-use of grey literature and other significant information resources is usually a symptom of failures in the capacity to handle information, which can express themselves in a number of forms.

\section{INFORMATION CAPACITY}

Robert Chambers characterises one central aspect of the way in which information fails to enter the collective consciousness of those in power as the phenomenon of the 'self-deceiving state'.[18] In this a kind of wilful blindness afflicts many of those who are supposed to know or find out. They may not wish to know all they could, because it might contradict the version of things that dictated by vested interests. These interests might call for the pursuit of particular goals or the following of particular orthodoxies. For instance, there might be too much money, time, and reputation invested in some project or programme to make it easy to let the facts interfere with its continuation.

Chambers also identifies a kind of arrogance of power which tends to render information irrelevant. His condemnation of those who let this arrogance close their minds to the promptings of an exterior reality is sweeping:

Throughout the development decades, most professionals have been confident in imposing on others their own beliefs, and the policies and programmes which follow from them. This includes academics, bankers, bureaucrats, consultants, planners, scientists and technical assistance personnel, and the staff of national ministries, field bureaucracies, donor agencies, and institutes for research and training, both in the North and in the South. Later, many of these beliefs and actions have proved astonishingly erroneous. [19]

This arrogance which tends to marginalise even the best and most appropriate information is not, however the only reason why information fails to achieve the effects which, in theory, it should. A glance at the type of difficulties that afflict the area of information and decision-making is needed to explain this.

It is true that sometimes the necessary information is not available at all: a nation can simply be information poor. The significance of the idea of information poverty is not, however, the same for everyone within a particular country. It is a description which usually applies much more to 
the situation of the citizenry in general than to those who hold any form of power or influence. Educated elites have not only a much better access to documentary information but it is also they who have access to computers and the computer-literacy to exploit them. They may not, however, tend to acknowledge the real strength of their position.

A very common reaction at many levels is still to suggest that the information available is simply insufficient to be of real assistance in decision making. There is plenty of reason nowadays to suggest that such statements are often excuses for decision making that is based on instinct, or as a responses to pressures (political, personal, business, etc.) that do not directly arise from the problem in hand. Lack of information is particularly frequently alleged when the decisions that need to be taken necessarily involve high levels of expenditure, or the delegation of important powers to NGOs, such as relief agencies in times of natural disaster. Lack of information is probably still such a familiar complaint because it can effectively shift responsibility on to some other agency. For this reason it is likely to be heard for some time yet. The contemporary problem, however, is that not only has the definition of adequate knowledge been much raised, but at the same time the volume of information which might be accessed has increased to a completely daunting extent.[20] Specific case studies of inadequate use of information, show how difficult it is for conventional information services to function within the harsh and sometimes dirty realities of decision making.

\section{CASE STUDY: NATIONAL ECONOMIC PLANNING IN MALAWI}

Malawi in the days of Kamuzu Banda, whose power ended in 1994, had a system of administration and planning ostensibly directed towards national development.[21] This system did acquire information and was supposed to apply it to planning for the achievement of a set of longterm goals which had been articulated in a published Statement of Development Policies. The responsibility for the planning process came to be located almost entirely in the Department of Economic Planning and Development, formed in 1985. The main flows of planning information into the Department came from the Treasury Department, which provided statistical projections for planning alternatives, the Reserve Bank of Malawi, which forecasted financial developments, and the National Statistical Office, which provided estimates of Gross Domestic Product. In general terms, the Department had the obvious means for macro-economic planning available, and the data was put together in an annual budget document, the Economic Report.

The various ministries responsible for sectoral programmes and projects submitted their estimates to the Department, where a process of measuring them against needs and resources was to take place. In addition, there was also a capacity for input from the regions via the system of District Development Committees, established in 1965. These were each chaired by the District Commissioner, who was the President's direct representative in the locality. Their membership included: government (representatives of the various ministries active in the District, notably Agriculture, Health and Education); politics (local MPs and officials of the ruling party); the traditional authorities (chiefs and village headmen); an ADMARC (the official Agricultural Development and Marketing Corporation) representative; and various coopted members. The deliberations of these bodies were to lead to local development proposals, which could be transmitted direct to the Department. In fact, uncertainties over world commodity prices, the political instability of the region, the unpredictability of the aid policies of donor countries, and the difficulty of obtaining reliable intelligence for accurate prediction, encouraged an improvisatory planning process and a tendency to emphasize short-term interests.

A system which on the surface had the elements necessary for the incorporation of national, sectoral and local data, was not in practice capable of producing a consistent policy direction. 
This tendency was exacerbated by the concentration of power in the hands of the President and his immediate advisers. Since none of the planning bodies, including the Department, had the capacity for long or medium term decision making, a de facto process of decentralisation to the Ministers and parastatal bodies occurred over time. This was not, however, really a decentralisation of decision making, more a delegation of functions and routine administration to the bureaucracy. The planning process, and all the information-related elements of it, were thus basically relegated to an exercise in public budgeting, with the Ministries manoeuvring for a better share of the budget which the Treasury had set out. The only real opportunities for innovation were when the ear of the President could be gained.

With the significance of information thus reduced it became noticeable that the mechanisms for gathering, organising and interpreting information tended to fail to operate effectively. For instance, information about the rural areas was gathered by the Agro-Economic Survey (AES), which provided a continuing service to collect and organise baseline data.[22] Data from the monitoring and evaluating of specific projects could then be set against AES data to give it context. The Survey's trained field enumerators and agricultural specialists collected and processed data, producing a steady flow of documentation. This contained precisely the detail of topography, soils, vegetation, climate and rainfall, infrastructure, settlement patterns and farming practices identified as needed by Stolper in 1966. However, the users of this baseline data gradually began to suggest that it was becoming detached from the planning requirements of the Ministries. The process seems to have become academic, producing information which was interesting in its own right, but not always giving direct answers to the questions planners were asking. This was arguably a symptom of a decline in morale in the government data-gathering system at large. If those involved in the planning process did not make proper use of the information which was provided for them, then the data-gatherers felt that there was little point in assembling data in ways that suggested a belief that it would be used to good effect.

\section{CASE STUDY: TECHNOLOGY TRANSFER IN KENYA}

In 1975 the Kenyan government encouraged Tate and Lyle, a UK-based sugar company to investigate the potential for producing ethanol from the output of the country's sugar mills, so as to meet some of its liquid energy requirements. Ethanol does not have the same energy content as petrol or diesel, but does have a higher octane rating and greater thermal efficiency. It can be used for many of the same purposes as petroleum products and its chief advantage in this case was that its production would partially insulate the country from the effects of the price and supply problems associated with imported fuels. In 1977, three proposals for ethanol projects were submitted and two, both from Kenyan companies with no ethanol experience, were accepted. However, despite considerable investment in an official partnership project, Kenya Chemical and Food Corporation (KCFC), and the licensing of another venture, Agro-Chemical and Food Corporation (ACFC), the programme has proved almost completely unsuccessful. Work on KCFC's plant stopped in August 1982, and whilst ACFC marketed its production for commercial blending with petrol in 1983, by 1985 its plant was operating at below 30 percent capacity. Government intervention to support sales in 1985 subsequently led to 75 percent use of plant capacity. Continuing research on production has been carried out by Kenya Industrial Research Development Institute (KIRDI) with little visible outcome.[23]

The process by which decisions were made on the ethanol programme reveals some of the reasons for the failures. At least two kinds of relevant intelligence gathering were neglected in the process. First of all, fundamental decisions should have been dependent on good market intelligence. Although the sugar industry was to be the basis on which the programme was built, 
no investigation was made of the industry's capacity to provide a consistent supply of the raw material for production. Indeed, the vulnerability of Kenya's sugar industry to world market trends, and the role of the special arrangements between producer and consumer countries, unrelated to production costs or demand, by which the bulk of world output was traded, were never mentioned in government documentation on the plans. Nor was there any serious analysis of Kenyan national energy requirements. The process, from the initial Tate and Lyle study onwards, was driven by a perceived need to find a domestic use for a product which was meeting problems in the export market, and which would cause pollution problems if it were dumped.

Secondly there were technology selection decisions in which local information should have had a crucial influence. When it is intended to produce ethanol from sugar cane, there are significant differences in the effectiveness of the different types of cane processing technology that can be used. The older method, open pan sulphitation, has higher energy costs than the more energy efficient vacuum pan process. This higher level of energy efficiency makes vacuum pan plants more suitable in principle for ethanol production. However, vacuum pan plants require higher capital investment and make greater calls on foreign currency resources than the open pan plants, which are versatile and better suited to deal with the inconsistent supply flows of cane from the Kenyan producers. A commitment to vacuum pans might seem more efficient in purely technical terms, but the use of open pans would need less capital and thus more easily admit local entrepreneurs to the industry. This technology would also have better matched the supply conditions in Kenya. In fact, the government chose to enter into technology acquisition agreements with foreign companies, which shifted the balance towards the purely technical imperatives and away from specifically Kenyan needs and conditions. Various unfavourable consequences for Kenyan farming have followed, particularly in the form of uneconomic prices for cane and its by-products.

The failures of the Kenyan ethanol programme were rooted in the lack of an independent institutional capacity to evaluate proposals. There was no real flow of relevant intelligence into the decision making process. Decisions were made on the basis of data submitted as part of project proposals, which was naturally selected by interested parties who were usually foreign investors and manufacturers The lack of independent data against which to validate proposals enabled companies which had no prior ethanol experience to present their cases as if they did have the relevant expertise. Investment by government departments in the programme further removed the possibility of independent validation, as departments were not required by law to subject themselves to any such procedure. Decisions were regularly based on the advice of civil servants who had no special expertise in the topic, and who were not required to obtain access to such expertise from outside. In hindsight the inadequacies of the ethanol programme were implicit in the decision making process and the information gathering capacity which supported it.[24]

\section{IMPLICATIONS FOR INFORMATION SERVICES}

These case studies may seem to suggest that in a context of corrupt and inefficient politics and governance there is no scope for information services which seek to serve rational decision making. There are, however, politicians, administrators and executives (even if they may often be a small minority) who seek to promote the general welfare by using the best intelligence available. They deserve access to services which arm them effectively in a difficult struggle. The general public also deserve to be informed as well as possible, through the agency of wellinformed media, so that they can play a positive part in the political process. The kind of assistance that is needed seems obvious, but the sheer difficulty of providing it has been stressed 
throughout this paper. By re-examining the nature of these problems, a view of what might be needed to address them does emerge. Looming over all the other problems, there is the issue of the sheer complexity of the information that must be used for intelligence purposes. This is in no way diminished by closer examination

Many of the techniques of modern development planning are utterly dependent upon high volumes of complex and detailed data. This is needed to indicate precisely the kind of programmes or facilities required. In planning health programmes, for instance, it is normal to examine statistics of the incidence and geographical distribution of diseases, also of the progress of immunization programmes, and various associated indicators of basic health and welfare. Beyond this, the planners of today would also require detail of dietary intake and the availability of essential foodstuffs, as well as data on the quality of water available across any region for which a programme was proposed. To satisfy such requirements more data is assembled from special surveys on particular topics and more regular data collection exercises of different kinds are carried out. They do not provide a sense of adequacy however, because the information requirement continues to be enhanced beyond what is already supplied.

Fuelling this inhibiting sense of the need for more and more information is the availability of an enormously increased potential capacity to collect and process data. Techniques for data gathering have progressed much beyond the formal (questionnaire-based) survey, or the crude counting techniques used to measure crops in the field or the numbers suffering from some particular health problem. Participatory techniques are now much used. They involve communities in the process of assembling data about themselves, and use techniques drawn from a number of academic disciplines, so as to develop a holistic view of problems. These have done much to improve the quality of knowledge that planners can acquire, but at the same time they have increased the volume of data and the difficulty of interpreting it.

There is also reason to believe that the availability of computer processing power has encouraged data collectors to adopt complex methodologies which tend to result in much enhanced outputs from the collection process. This has meant that those who do have good information access quite often obtain much more than they can handle. In this situation, local and national databases in profusion actually provide so much detail that their content can become quite detached from decision making. Just because it is possible to generate much more information, there is the temptation to do just that. The almost inevitable outcome of this is for the information to be very good, in an abstract or academic sense, but detached from the practical realities of government or business, which were the reason for its creation in the first place. There is a sheer surface gloss to information derived from sophisticated collection techniques, subject to automated processing, and, most of all, presented with a plethora of visually pleasing charts, tables, and graphs. This can easily conceal a lack of relevance, or fail to indicate the complexities which underlie a beautifully comprehensible visual presentation generated by the computer.

Because there is information of many kinds passing through the ministries and other institutions of the state, there is always the temptation to assume that it must contain the answers that are required in a particular planning or administrative contingency. This may or may not be true, but to find out whether or not it is true can be too daunting a task for even a determined researcher or politician. Information may be collected, stored and disseminated in considerable quantities, but it may be very hard to find out just what is being collected and made available by any given institution. Quite simply, no one may know just what information is being produced by which organisation and in what forms it is available. Information is collected at all sorts of levels, national and local, it is collected in relation to particular sectors, education or health for instance, and by different agencies, official and non-governmental. At some points in this landscape, there may be those who guard their information for the prestige and influence it might 
bring: there may be those who simply do not have the resources or guidelines available to them to distribute their information effectively. This could be identified as a problem of lack of an official policy on information, or, more generally a lack of a full sense of information as an important resource whose value-in-use needs to be maximised at every possible opportunity. However, the most important inference which can be drawn from this examination of complexity is that the information which is available is quite obviously not in forms which are convenient for the use of busy decision makers.

Statistics services, for instance, collect very large volumes of data which they process in ways which allow it to be expressed in tables, often permutated in various alternative formats, and generally used to permit a very full and multi-faceted documentation of whatever aspect of life and society has been measured by counting. When such riches are possible, it may be agonizing for the service to digest the information into a compact report format, even though there may be a certain awareness that only in a compact and scannable form does the information stand any chance of impinging on the consciousness of some maker of policy. Similar things can be true of documentary resources. A library may have books, articles and grey literature on a topic in sufficient profusion to enable several theses to be written, but anything more than a digest of some of the content of the most relevant items will not be acceptable at the top level of an organization. The material tends to be collected because it might some day be useful, rather than because it can be shown that it will be needed for predictable specific purposes. These are failure which can be remedied, even though the remedies will not be simple to apply.

\section{REFINING INFORMATION FOR SOCIAL INTELLIGENCE}

Before information can be submitted to those who might use it in decision making, it needs to be processed for effective use. In this first place this might simply involve what is known as consolidation of information. Ideally, however, it could go somewhat further. The information could be refined for use. Consolidation, as described by Saracevic and Wood,[25] attempts to provide users with all that is basic and essential about a document or group of documents, as far as possible from the point-of-view of the creator of the document. Refining seeks to take out all that is really valuable and significant from a document, or a variety of non-documentary sources, putting it in a form especially designed to help a particular user or users. Consolidation is still the action of the librarian or other similar information professional, seeking to make sure that documentary information is available for effective use 'just in case' it will be needed. Refining is the task of a subject expert, or member of a management team, so that often fragmentary information sources are interpreted in combination with each other, and the interpretive summary made available 'just in time'.

The focus in information refining is on creating a wholly new and probably quite ephemeral information synthesis, rather than on an information product designed for use and re-use.[26] It is quite clear that grey literature and other information resources deliberately stored by information professionals, however well-organized, are passive. They wait to be used, and to a great extent, they are not used at all. In the refining process, documents are read by a specially trained analyst, as opposed to merely being stored for possible future use. The process results in reports which offer expert interpretation and reveal cross-links not obvious from single sources. To achieve this the analyst applies to the sources techniques of content analysis originally developed for military intelligence, the social sciences and literary criticism.

This involves the analyst pulling together significant data on a topic from the whole range of available sources. This is done according to a content classification scheme derived from the experience of working in the subject area concerned. Current computer network and database 
facilities make a major contribution to the process of identifying the items to be analyzed. The analyst then writes short narratives using information and extracts from the sources identified as related to the topic. A significant aspect is that the analyst seeks to retain the original 'voices' of those who reported the facts in the first place, so that their perceptions are not rubbed out during the refining process. What should then emerge is a systematic account of events, seen through the eyes of the original reporters, as interpreted by the analyst. Such narratives have the ability to reveal the types of trend which may not be at all clear from reading an isolated document or particular form of documentation. Their creation is arguably the apogee of the intelligence process.

Decision makers with refined information on their desks have little excuse for poor policy and implementation. If the intelligence is available to them the responsibility falls squarely upon their shoulders and their answerability in the forums of public debate is much clearer than it has been in the past. Information workers, in turn, should not make the excuse that because they have collected and hold the relevant grey literature and other materials their responsibility is fully discharged. Unless their holdings are, to some extent at least, fed into a refining process the existence of these holdings represents potential rather than achievement. The provision of social intelligence may not be precisely the duty of each individual information worker, but participation in the intelligence process is indeed the true justification of their employment.

\section{NOTES}

1. B. Cronin and E. Davenport, The compound eye/I: an introduction to social intelligence. In: B. Cronin, ed. Information, development and social intelligence, London, Taylor Graham, 1996, 7-12. p.7

2. S. Dedijer and N. Jequier, eds. Intelligence for economic development: an enquiry into the role of the knowledge industry, Oxford, Berg, 1987.

3. W.F. Stolper, Planning without facts: lessons in resource allocation from Nigeria's development, Cambridge, Mass., Harvard University Press, 1966.

4. E.E. Woherem, Information technology in Africa: challenges and opportunities, Nairobi, ACTS Press, 1993.

5. R. Cruise O'Brien, Information, economics and power: the North-South dimension. London, Hodder and Stoughton, 1983.

6. S. Roy, Structural adjustment programmes, the economy and the rural sector. Africa Quarterly, 30, 1991. 112.

7. S. Please, Beyond structural adjustment in Africa. Development Policy Review, 10, 1992. 289-307. p.293.

8. Organization of African Unity. Lagos Plan of Action for the Development of Africa 1980-2000. Geneva, International Institute for Labour Studies, 1981.

9. World Bank. Accelerated development in sub-Saharan Africa: an agenda for action. Washington, D.C., World Bank, 1981.

10. World Bank. Sub-Saharan Africa: from crisis to sustainable development. Washington, D.C., World Bank, 1989.

11. J.D. Wolfsohn, 1996 Annual Meeting Speech. Washington, D.C., World Bank, 1996. Para 48. 
12. United Nations Economic and Social Council, Economic Commission for Africa, Africa's Information Society Initiative (AISI): an action framework to build Africa's information and communication infrastructure. Addis Ababa, ECA, 1996.

13. K.J. Mchombu, Information management in Africa: an uncharted terrain. FID News Bulletin, 42, 1992. 186-189. p.187.

14. M. Cook, Information management and archival data. London, Library Association, 1993.

15. P. Sturges, Using grey literature in informal information services in Africa. Journal of Documentation, 50, 1994. 273-290.

16. P. Sturges and G. Chimseu, Information repackaging in Malawi. African Journal of Library, Archives and Information Science, 6, 1996. 85-93.

17. P. Sturges, The political economy of information: Malawi under Kamuzu Banda 1964-1994. In: J. Feather ed. Transforming libraries and educating librarians: Essays in memory of Peter Havard Williams London, Taylor Graham, 1997. 57-73.

18. R. Chambers, The self-deceiving state. IDS Bulletin, 23, 1992. 31-42.

19. R. Chambers, All power deceives. IDS Bulletin, 25, 1994. 14-26. p.14.

20. S. Davies, Introduction: information, knowledge and power. IDS Bulletin, 25, 1994. 1-13.

21. J. Kaunda, The administrative organisation and processes of national development planning in Malawi. In: G.C.Z. Mhone, ed. Malawi at the crossroads: the post-colonial political economy, Harare, Sapes Books, 1992. 50-89.

22. D. Green and N. Maddock, Facts for planning rural development: some lessons in the administration of data collection from Malawi. Agricultural Administration and Extension 24, 1987, pp.33-48.

23. R. Onyango, Indigenous technological capacity: can social intelligence help? A Kenyan case study. In: B. Cronin, ed. Information, development and social intelligence. London, Taylor Graham, 1996. 164-181. pp.168-9.

24. C. Juma, Market restructuring and technology acquisition: power alcohol in Kenya and Zimbabwe. Development and Change 16, 1985. 39-59.

25. T. Saracevic and J.B. Wood, Consolidation of information: a handbook on evaluation, restructuring and repackaging of scientific and technical information, Paris, Unesco, 1981. (PGI/81/WS/16).

26. J. Wyllie, The need for business information refineries. Aslib Proceedings 45, 1993. 97-102. 